\title{
A Study on Positive Transfer of Native Language and Second Language Teaching Methods
}

\author{
Chen Chen \\ School of Foreign Languages, Shanxi Normal University, Linfen, China
}

\begin{abstract}
Native language is one of the important factors that affect second language acquisition (SLA). However, compared with the heated discussion about the negative transfer of native language, the positive transfer of native language lacks due attention. Taking Chinese and English as a case study, this paper first reveals the similarities between the two languages, then discusses the positive effects of native language on SLA, and finally explores English teaching methods so as to promote the positive transfer of native language and reduce the negative transfer.
\end{abstract}

Index Terms — native language, second language acquisition, positive transfer, teaching methods

\section{INTRODUCTION}

Native language transfer is a complex phenomenon. It has already attracted many scholars' attention in the study of SLA. Since the 1950s, scholars began to study the impact of native language on SLA. With the development of transfer theory, more and more linguists begin to pay great attention to the relationship between native language and SLA. The influence of native language on SLA can be divided into two kinds: positive effects and negative effects. The positive effects, namely, positive transfer, promote second language acquisition, while the negative effects, namely, negative transfer, refer to the interference and obstruction of native language to SLA. However, for a long time in the study of SLA, when it comes to native language transfer, people usually focus on the negative transfer of native language, while the positive transfer of native language has not received sufficient attention. What's more, due to the influence of Chinese way of thinking and culture, Chinglish appears in the process of English learning. As it does not conform to English grammar and the norms of English communication, Chinglish is difficult for people in English-speaking countries to accept. Thus, it has been criticized and rejected by most English teachers. Influenced by behaviorism, many scholars believe that native language is a great hindrance to SLA. And also there is one extreme conception, that is, the impact of native language on SLA is completely negative, but, as a matter of fact, that is not the case.

The theory of SLA holds that native language is not only an indispensable background and foundation for second language learning, but also a resource that can be developed and utilized. Native language plays a very important role in the process of SLA. Language transfer is the result of interaction between the target language and native language that has been learned before. It should be pointed out that the similarities between the native language and the second language in vocabulary, grammar and culture will promote second language acquisition to great extent. This paper holds that it is necessary to make proper and rational use of native language resources to promote the learning of target language.

At present, most of the studies about the influence of the native language on second language acquisition focus on negative transfer, while the study about the positive effects of native language on SLA is still limited. According to the theory of SLA, native language is not only an indispensable background and basis for second language learning, but also a resource that can be developed and utilized. Based on this, in the paper, the author attempts to take Chinese and English as a case study to explore the role of positive transfer of native language in the process of SLA from the three aspects of language thinking, vocabulary, grammar, and discuss how to make full use of the commonalities between L1 and L2 in SLA, overcome and avoid negative transfer of native language.

\section{A Brief Introduction to NATive Language TRANSFer IN SLA}

Transfer was originally a psychological concept, which refers to the influence of acquired knowledge, skills, even methods and attitudes on learning new knowledge and skills. In the mid-18th century, many scholars began to explain and study transfer systematically. Simply speaking, learning transfer is the influence of one kind of learning on another. Language transfer refers to "the influence of one language on learning another" (Longman Dictionary of language teaching and applied linguistics 1992). According to the results of language transfer, it can be divided into positive transfer and negative transfer. The process of former learning promoting the latter learning is called positive transfer, while negative transfer refers to that the former learning hinders the latter learning. As an important factor affecting SLA, language transfer is a major research area. In essence, the differences between L1 and L2 produce negative transfer. On the contrary, the similarities between them produce positive transfer. 


\section{A. Negative Transfer}

Negative transfer refers to that the knowledge and thinking habits of native language seriously affect and hinder people's learning of second language. Many scholars believe that, in the process of SLA, under the influence of native language, students often have errors at all levels, such as pronunciation, vocabulary, syntax, writing compositions, etc.

\section{B. Positive Transfer}

Both Chinese and English belong to languages, and they have common features in many aspects. In the process of SLA, if L1 has more similarities with L2, it is easier to have a good command of the second language for second language learners. This process of language similarities promoting SLA is called positive transfer. For example, Japanese and Chinese are similar in written form; French and English are similar in grammar system and written form. Such language similarities undoubtedly help second language learners to learn a second language. In the process of SLA, many students unconsciously use grammatical rules and methods used in learning their native language. If there are more commonalities between L1 and L2, students can master the grammatical rules of L2 more easily and accelerate the learning speed for L2 more effectively, which can prove that the positive transfer of native language plays a vital role in promoting the learning of second language.

\section{Positive EfFects of THE NATive LANGUAGE ON SLA}

As mentioned above, some researchers believe that native language is bound to bring negative effects to SLA, and the 'interference' or 'influence' of native language should be got rid of. Nowadays, all kinds of high schools and universities in China are actively promoting all-English teaching mode. This teaching mode is not limited only to English classes, and many professional courses are also required to do so, which is the typical reflection of neglecting the positive transfer of native language. The biggest advantage of this teaching mode is that it can create all-English learning environment for foreign language learners, effectively develop students' sense of language to a large extent, and improve students' communication ability and intercultural communication consciousness. However, it would make students feel difficult to learn a foreign language, especially for students with poor academic performance. Lado attributed the main difficulties of foreign language learning to the differences between native language and target language. According to his hypothesis, the similarities between L1 and L2 tend to produce positive transfer. In the following part, the positive transfer of native language will be discussed in detail from several aspects.

\section{A. Native Language Thinking}

Language thinking is a mental process of using language to describe and express the objective world phenomena. Chinese and English have similar psychological basis, process and ultimate goal of thinking, but they are different in the means or methods of thinking. Thinking operates before the process of using language to describe the world. In this sense, when learning a second language, the positive transfer of native language thinking plays a crucial role. A large number of studies have shown that when people learn a second language, they often unconsciously use native language thinking to understand a foreign language. That is to say, they have a strong dependence on native language thinking, especially when reading passages and writing a composition using target language, which is inevitable. Some investigation results also indicates that, in academic achievement, students who do well in reading and writing with the help of native language thinking are significantly better than those who use less or do not use native language thinking at all. Therefore, it is concluded that the transfer of native language thinking plays an important role in promoting students' second language acquisition.

\section{B. Vocabulary}

\section{Features}

Firstly, there is a large vocabulary in English. Each word may have different meanings. Similarly, a Chinese character, in most cases, can also convey many different meanings. For example, 'communication' in English and '空' in Chinese both contain multiple meanings.

Secondly, in word formation, there are many similarities between English and Chinese. The first type is compounding. For example, in English, the word 'football' consists of two parts: 'foot' and 'ball'; 'website' is composed of 'web' and 'site'; 'newspaper' consists of 'news' and 'paper'. Likewise, there are also many compound words in Chinese, for example, '电脑'(dian nao), which means 'computer', '手机'(shou ji), which means 'mobile phone', “饭桌'(fan zhuo), which means dining-table, 课桌 (ke zhuo), which means 'desk', and '水杯' (shui bei), which means 'water cup'.

Another type of word formation is derivation, which means that a word is composed of root and affix. In English, 'happy' means that one person is very delighted, whereas 'unhappy', which means displeasure, consists of 'un' and 'happy'; 'ability' means one person is competent, whereas 'disability' means incompetence. In Chinese, the Chinese character ‘胡' is composed of ‘古'(gu) and ‘月'(yue); ‘艳” is composed of ‘丰'(feng) and ‘色'(se).

A Chinese character, in most cases, is used as different parts of speech and accordingly contain different meanings, such as the Chinese characters '花(hua)', ‘明(ming)', etc. '花' has different usages in terms of contexts. In the sentence 
“花园里有很多小鸟’(hua yuan li you hen duo xiao niao), it is used as a noun, meaning 'flowers'. In the sentence ‘他花 钱如流水'(ta hua qian ru liu shui), it is used as a verb, which means 'spending'. In the sentences, “他爷爷的眼睛是老 花眼'(ta ye ye de yan jing shi lao hua yan), ‘他很花心’(ta hen hua xin), and ‘他衣服的颜色很花'(ta yi fu de yan se hen hua), it is obviously used as a adjective. Such linguistic phenomena are also common in English. Let's take the word 'right' as an example. It is a noun in "every citizen has the right to pursue happiness", an adjective in "you are right", and an adverb in "you must put down the gun right now". To sum up, there are different ways of word formation in English, but it is not difficult to understand them because they are quite similar to Chinese.

For second language learners, they should attach great importance to native language's similarities to second language and use Chinese vocabulary knowledge to associate and memorize English words. Teachers can lead them to take advantage of native language transfer to learn vocabulary in SLA.

2. Word class

TABLE I

\begin{tabular}{l|l|l}
\hline \multirow{2}{*}{$\begin{array}{l}\text { Classification of } \\
\text { content words }\end{array}$} & Chinese & English \\
\cline { 2 - 3 } & veun & noun \\
\cline { 2 - 3 } & adjective & verb \\
\cline { 2 - 3 } & adverb & adjective \\
\cline { 2 - 3 } & pronoun & adverb \\
\cline { 2 - 3 } & numeral & pronoun \\
\cline { 2 - 3 } functional words & classifier & numeral \\
\cline { 2 - 3 } & interjection & \\
\cline { 2 - 3 } & onomatopoeic word & conjunction \\
\cline { 2 - 3 } & preposition & preposition \\
\cline { 2 - 3 } & modal verb & modal verb \\
\cline { 2 - 3 } & modal particle & interjection \\
\cline { 2 - 3 } & & article \\
\hline
\end{tabular}

The table above clearly shows the similarities and differences between English and Chinese in the classification of parts of speech. The similarities are as follows: firstly, there are two types of words: content words and functional words; secondly, the content words include six categories: noun, verb, adjective, pronoun, adverb and numeral; thirdly, in the functional words, the two languages both include conjunction, preposition and modal verb. Their differences are that the quantifier, interjection, onomatopoeia and modal particle are unique to Chinese, and the interjection and article are unique to English.

The above analysis shows that Chinese students should make full use of their Chinese vocabulary knowledge to understand the basic usage of English words, so as to yield twice the result with half the effort. When learning a second language, second language learners can use language similarities to promote positive transfer, and find some skills and methods as many as possible to make English learning easier and more interesting.

\section{Grammar}

\section{Syntax}

a. Basic sentence structure

The similarities between English and Chinese are reflected not only in vocabulary, but also in syntax. Syntactic similarities are mainly manifested in basic sentence structures. Table II in the following clearly reflects the similarities between English and Chinese in sentence structures.

TABLE II

\begin{tabular}{l|l|l}
\hline $\begin{array}{l}\text { Basic sentence } \\
\text { structures }\end{array}$ & Sample sentences ( English) & Sample sentences ( Chinese) \\
\hline $\mathrm{S}+\mathrm{V}$ & She is drawing & 她在画画 \\
\hline $\mathrm{S}+\mathrm{V}+\mathrm{O}$ & She is brushing her hair & 她正在梳头 \\
\hline $\mathrm{S}+\mathrm{V}+\mathrm{P}$ & She is a student & 她是一名学生 \\
\hline $\mathrm{S}+\mathrm{V}+\mathrm{O}_{\mathrm{i}}+\mathrm{O}_{\mathrm{d}}$ & She gave her father a special birthday gift & 她给了她爸爸一件生日礼物 \\
\hline $\mathrm{S}+\mathrm{V}+\mathrm{O}+\mathrm{C}$ & She always kept her bedroom clean & 她总是保持卧室干净整洁 \\
\hline
\end{tabular}

From the above table, we can see that the five basic sentence patterns in English are exactly the same as that in Chinese. Therefore, in grammar learning, English learners can take advantage of such commonalities, that is, use the transfer of Chinese properly to improve learning efficiency.

b. Structure of prepositional phrase 


\begin{tabular}{l|l|l}
\multicolumn{2}{c}{ TABLE III } \\
\hline Prepositional phrase & Sample sentences ( English) & \\
& & \\
\hline \multirow{2}{*}{$\begin{array}{l}\text { preposition+ } \\
\text { object } \\
(\mathrm{P}+\mathrm{O})\end{array}$} & I am in Beijing & 我在北京 \\
\cline { 2 - 3 } & He is reading in the classroom & 他在教室看书 \\
\cline { 2 - 3 } & They are at work & 他在工作 \\
\cline { 2 - 3 } & Two kids are under the tree & 两个小孩在树下 \\
\hline
\end{tabular}

The above examples show that English and Chinese have a great similarity in the use of prepositions, that is, they both adopt the prepositional structure, namely "P+O", following the syntactic order of preposition before object. (The object can be a noun or pronoun)

c. Modifiers of nouns and adjectives

TABLE IV

\begin{tabular}{|c|c|c|c|}
\hline \multicolumn{2}{|l|}{ Modifier type } & $\begin{array}{l}\text { Sample sentences } \\
\text { (English) }\end{array}$ & $\begin{array}{l}\text { Sample sentences } \\
\text { (Chinese) }\end{array}$ \\
\hline \multirow{2}{*}{$\begin{array}{c}\text { modifiers of } \\
\text { nouns }\end{array}$} & $\mathrm{n}$ & a story book & 故事书 \\
\hline & adj & a beautiful woman & 漂亮的妇女 \\
\hline $\begin{array}{c}\text { modifiers of } \\
\text { adjectives }\end{array}$ & $\mathrm{adv}$ & 这个问题太难了 & $\begin{array}{l}\text { This question } \\
\text { extremely difficult }\end{array}$ \\
\hline
\end{tabular}

The above table reveals the commonalities between English and Chinese in terms of noun and adjective modifiers: in the two languages, nouns and adjectives are used to modify nouns, and adverbs to modify adjectives. This common feature of the two languages in terms of modifiers is essentially a language rule that can be summarized. If students can master this linguistic point in the process of learning English, they will achieve surprisingly good effects in memorizing vocabulary, doing translation and writing a well-organized composition.

2. Grammatical phenomena

English and Chinese languages have great similarities not only in syntax, but also in some grammatical phenomena.

a. Inversion

Different from declarative sentence pattern, inversion refers to reversing the order of some elements in a sentence to highlight a certain content and strengthen the mood. It can be understood as a grammatical rule or a rhetorical device, which is used in both English and Chinese. Some typical examples are as follows:

Example1: 已经去上课了, 他们。(yi jing qu shang ke le, ta men )

Example2: 去哪儿啊, 你? (qu na er a, ni?)

Example3: 他站在那儿, 静静地。(ta zhan zai na er, jing jing di)

The first Chinese sentence means that they have gone to class. Example2 means that where you are going. In both cases, the subject is placed at the end of the sentence, which belongs to the subject predicate inversion type. The third one means that someone is standing there quietly. The sentence element '静静地' is put at the end of the sentence, which plays the role of supplementary explanation.

Example4: There are a number of students in the lecture hall.

Example5: When he ran to the door, there stood a mid-aged man with a lantern in his hand.

Example6: Not until he woke up did he find out what happened.

There are two kinds of inversion in English: full inversion and partial inversion. Example4 and example5 both belong to full inversion. Example6 belong to partial inversion.

It can be seen from the above examples that inversion of sentence components occurs in both English and Chinese.

b. Ellipsis

Language users omit one or more components of a sentence so as to avoid repetition. This grammatical phenomenon is called ellipsis. As an important linguistic device, ellipsis is used in both English and Chinese.

Example7: A: 是他做的饭吗? (It is he that cooked the meal?)

$\mathrm{B}$ : 是他(是的) (Yes)

Example8: A: Did you finish your homework?

B: Yes, I did.

In example7 and 8, only the subject appears, and the predicate part after the subject is omitted.

Example 9: A: 干啥去? (What will you do?)

B: 做家务 ( doing some housework)

Example10: A: How is your mother today?

B: Much better.

In the two cases above, the subject is omitted, which is the similarity between the two languages. Both of the two speakers know the person they are talking about, so the subject is omitted for brevity.

In addition, it should be noted that, firstly, the ellipsis of the subject in a sentence is very common in Chinese. For 
example, “这个问题要认真考虑一下(zhe ge wen ti yao ren zhen kao lv yi xia)’. Such expression is grammatical and also completely understandable to the hearer. However, if it's translated into English, the subject 'you' or "we" should be added. So we can translate the Chinese sentence like this: we should consider this matter seriously. Secondly, in order to avoid language repetition, the omission of the conjunction is also quite common in Chinese subject-subordinate complex sentences. For instance, “明天不下雨, 我就出席朋友的婚礼( ming tian bu xai yu, wo jiu chu xi peng you de hun li)'. This sentence implies a conditional relationship, but if it is translated into English, the conjunction "if" should be added. So the corresponding English expression should be: if it doesn't rain tomorrow, I will attend my friend's wedding ceremony. Under the influence of Chinese, which is their native language, when doing the translation, students often list the sentence components together one by one, which is not in line with English grammar rules and expression habits.

c. Imperative mood

Imperative mood is also one of the similarities between English and Chinese. It is a language phenomenon which expresses direct command, advice or request. In imperative sentence, the subject is often omitted. In this sense, imperative sentences belong to a type of elliptical sentences.

Example11: Speak more slowly, please.

Example12: 起来! 快去救火! (Get up, and put out the fire)

Imperative mood is used in the two examples. The only difference is that the English example11expresses a request, while the Chinese example12 expresses a command.

Throughout our country's current English course education, in English learning, Chinese students often confuse English learning with Chinese learning, especially the learning of grammar. The influence of Chinese grammar and culture on them is so deeply-rooted that it is easy for them to make grammatical mistakes in SLA. Therefore, when learning English grammar, English learners ought to discover the similarities between Chinese and English as many as possible so as to promote positive language transfer, and, in the meantime, find the differences so that negative transfer of language can be transformed into positive transfer of language.

\section{ON TEACHING METHODS}

\section{A. The Role of Native Language-Indispensable Foundation and Background}

In the process of English learning, Chinese is always the background and foundation and plays an indispensable role. Learning English at the advanced stage is actually a matter of logical thinking and language organization. If students do not master Chinese well enough, then English learning in advanced stage will be limited to some degree.

Communicative competence is an important criterion for second language learning. We can find that students with strong communicative ability in foreign languages are not poor in the application of their native language. In the process of language writing and oral communication, second language learners unconsciously use the knowledge of their native language to organize sentences and express ideas, which can be understood as a second language learning strategy. When talking about simple topics, students are less dependent on their native language. On the contrary, when discussing more complex topics, as there are often no ready-made language materials, they have to solicit help from their native language, collect their thoughts in their native language, and then express their ideas using a second language. What's more, it is impossible for adults to learn a foreign language faster than children without the help of knowledge and intelligence from their native language. Understanding is an essential part of learning any language. Language information that is completely incomprehensible is meaningless for acquisition. Language information needs to be processed by the brain and then output by the brain. Therefore, understanding is also a prerequisite for language generation and output. The important foundation of foreign language understanding is the knowledge, intelligence, cognition and ability for the native language as well as the understanding and experience of the objective world.

\section{B. Analysis and Discussion on English Teaching Methods}

1. Guiding students to pay attention to positive transfer of L1 and apply it to SLA

Teachers can guide students to use their knowledge of L1 to help them master L2 more effectively and quickly. And also they can help students compare native language and target language by various ways, and find out the similar characteristics, which help students to remember and master foreign language knowledge. For example, when the teacher explains the word "undermine", he or she can explain it by giving a detailed illustration using L1 so that students' learning efficiency is improved.

2. Reducing negative transfer

Vocabulary is closely related to historical and cultural background. People of different cultures have different ways of thinking, so they have different understanding and values of the world. In most cases, it is quite difficult to find the exact corresponding words in the two languages. For example, although some words in Chinese and English seem to correspond, their actual meanings are quite different. Cultural differences make it difficult to find equivalent words. For example, "American Dream" in English is related to American history, and it is difficult to find Chinese equivalent words. Although some words have the same meaning in Chinese and English, they have different extended meanings. For example, "white" is associated with funeral in Chinese tradition, while "white" symbolizes "purity" in the west, and 
the bride wears "white" wedding dress in the wedding.

Based on the analysis above, teachers should emphasize that English and Chinese are two different languages, so that the negative transfer of English to Chinese is weakened. In the process of learning English grammar, most of the learners often make mistakes under the influence of Chinese, so we ought to use the method of comparative analysis to avoid the negative transfer of Chinese. Through this method, students will have a profound understanding of the similarities and differences of a certain grammar point between two languages in a short time, which is more conducive to the mastery of English grammar. For example, in the teaching of English sentence patterns, no matter in English or in Chinese, their internal components are basically the same, including subject, predicate, object, attribute, adverbial and complement, and their basic sentence patterns are also basically the same, so when analyzing English sentences, teachers can take the teaching method of contrastive analysis to help students better identify sentence components.

3. Two basic principles

a. Clarity of purpose

Cook (2001) argues that L1 should be borrowed when the grammar is hard to understand for English learners. L1 can be used to explain linguistic difficulties of grammar, vocabulary. It can be seen that the use of native language is not aimless, but to enhance students' understanding of English. Therefore, L1 can be employed in the reading class involving comprehension. In listening and speaking classes, which focus on language application and practice, the use of $\mathrm{L} 1$ is unnecessary.

b. The principle of moderation

Some experts have pointed out that the time of using native language in foreign language class cannot exceed $10 \%$. We all know that foreign language teaching is an input process. Only sufficient input ensures sufficient output. The time and quantity of L2 input must be guaranteed in foreign language classes. Hence, the principle of moderation should be adhered to in English teaching.

\section{CONCLUSION}

It is very important to make full use of L1 transfer in the process of SLA. Only by overcoming negative transfer and making use of positive transfer can SLA be promoted. In daily teaching and learning, we should pay much attention to the following aspects:

In terms of vocabulary, the key to English learning lies in the accumulation of linguistic knowledge. Through accumulation, students can classify the knowledge we have learned and summarize the similarities and differences between Chinese and English, which would help them remember English words. Some special lexical collocations or expressions should be identified according to context, cultural background and expression habits. Many words in English do not correspond to the concepts expressed by Chinese words. This requires us not to teach vocabulary by putting it in a certain cultural background.

In the aspect of sentence pattern, we should strengthen comparative sense, pay attention to the similarities between Chinese and English, and make use of them. We can develop and strengthen our English language sense by reading more English newspapers, novels and so on.

In terms of culture, language is a kind of profound historical and cultural accumulation, that is to say, "language cannot exist without culture." In the long history of human civilization, it is the habits and beliefs of life--cultural conventions that affect the languages of all nations. Therefore, to understand the language, one must understand the culture, and to understand the culture, one must understand the language. They complement each other. This requires us to improve our sensitivity to cultural differences, avoid or reduce the impact of negative cultural transfer on English learning, so as to deepen the mutual understanding between different cultures. In this way, cross-cultural communication can be carried out smoothly.

It is precisely because there are various differences and similarities between English and Chinese that we are required to study the relationship between the two languages carefully when learning English. To sum up, anyway, we need to make full use of and give full play to the positive transfer of Chinese with the help of Chinese knowledge and accumulated Chinese learning experience, and try to prevent the negative transfer of Chinese, so as to improve the quality and efficiency of English learning.

\section{REFERENCES}

[1] Bao Zhiru. (2014). On the Enlightenment of L1's syntactic transfer to SLA on college English writing. Teaching of foresty region, 7, 35-36.

[2] Cook V. (2001). Using the first language in the classroom. Canadian Modern Language Review, 57, 402-423.

[3] Gan Li. (2004). The Negative Interference of Chinese and Teaching of English Syntax. Shan Dong Foreign Language Teaching Journal, 4, 28-30.

[4] Kim, D. Y. Pan, and H. S. park. (1998). High - versus low- context Culture: a comparison of Chinese, Korean, and American cultures. Psychology and Marketing, 15( 6), 507 - 521.

[5] Lou Lijie.(2013). On the similarities and differences between Chinese and English measure words. Journal of Hubei University of Science and Technology, 33(9), 200-202.

[6] Liu Xiangqing, Jia Dejiang. (2004). A comparative study of rhetorical functions between Chinese quantifiers and English scales. 
Journal of Xi an International Studies University, 12(3), 29-31.

[7] Lu Xiaoyong. (2002). On the positive influence of mother tongue on second language acquisition. Foreign Language World, 4 , 11-15.

[8] Peng Cheng, Wang Tongshun. (2016). A study of the influence of mother tongue transfer on collocation acquisition in L2 mental lexicon. Contemporary Foreign Languages Research, 4, 34-38, 44.

[9] Su Liuhua. (2000). A study of the influence of mother tongue transfer on second language learning. Journal of Beijing International Studies University, 4, 44-52.

[10] Tang Zhenhua. (2000). On the negative transfer of culture in Chinese-English Translation. Foreign Languages and Their Teaching, 11, 47-50.

[11] Wang Wenjing. (2017). Positive effect of native language on second language acquisition. Journal of Xinyang College of Agriculture and Forestry, 27(2), 85-87.

[12] Xi Liyun, Zhang yao.(2013). On the potential influence of mother tongue in second language acquisition. Journal of Luohe Vocational Technology College, 12(3), 175-176.

[13] Yuan Caihong, Lang Hongqin. (2000). A study on the negative transfer of mother tongue culture and English Teaching. Foreign Languages and Their Teaching, 8, 46-47.

Chen Chen was born in Changzhi, China in 1992. He received his Bachelor's degree in literature from Harbin Normal University, China in 2015. His major field of study: history.

$\mathrm{He}$ is currently a postgraduate student in the School of Foreign Languages, Shanxi Normal University, Linfen, China. His research interests include applied linguistics and translation. 